\title{
Impact of Intake Water Temperatures on Reticular Temperatures of Lactating Dairy Cows
}

\author{
J. M. Bewley, ${ }^{1,2}$ M. W. Grott, M. E. Einstein, and M. M. Schutz \\ Department of Animal Sciences, Purdue University, West Lafayette, IN 47907
}

\begin{abstract}
Automatic temperature recording may allow early detection of disease, estrus, heat stress, and the onset of calving. The phase IV Cattle Temperature Monitoring System (MaGiiX Inc., Post Falls, ID) utilizes a passive bolus equipped with a temperature sensor, a stationary panel reader to query the bolus, and software to collect, analyze, and display data. One potential limitation to collection of reticular temperatures is the effect of water temperature and consumption on recorded temperatures. Two replicated $3 \times 3$ Latin square experiments were conducted at the Purdue Dairy Research and Education Center to assess the impact of water intake on reticular temperatures using the Cattle Temperature Monitoring System. Nine high-producing, mid-lactation, second-parity cows with low somatic cell counts were selected. Before administering a water treatment, access to feed and water was restricted for at least $2 \mathrm{~h}$. Baseline reticular temperatures were established from measurements before water intake. In experiment 1, treatments were $25.2 \mathrm{~kg}$ of hot water $\left(34.3^{\circ} \mathrm{C} \pm 1.0\right)$, warm water $\left(18.2^{\circ} \mathrm{C} \pm 0.4\right)$, or cold water $\left(7.6^{\circ} \mathrm{C} \pm 0.4\right)$. In experiment 2 , treatments were $18.9 \mathrm{~kg}$ of body-temperature water $\left(38.9^{\circ} \mathrm{C} \pm 0.2\right)$, cold water $\left(5.1^{\circ} \mathrm{C} \pm 0.4\right)$, or control (no water). Following water intake, reticular temperatures were collected for $3 \mathrm{~h}$. In experiment 1 , an initial dramatic decrease in reticular temperature was observed followed by a gradual increase toward baseline. Least squares means for maximum drop in temperature were $8.5 \pm 0.5,6.9$ \pm 0.5 , and $2.2 \pm 0.5^{\circ} \mathrm{C}$ for cold, warm, and hot water treatments, respectively. Yet at $3 \mathrm{~h}$, reticular temperatures did not return to the baseline. In experiment 2, control cows remained within the baseline confidence interval through the observation period, and cows receiving body temperature water experienced an initial decrease in temperature $\left(0.4 \pm 0.2^{\circ} \mathrm{C}\right)$ with a return to
\end{abstract}

\footnotetext{
Received March 9, 2008.

Accepted June 30, 2008.

${ }^{1}$ Corresponding author: jbewley@uky.edu

${ }^{2}$ Current address: Department of Animal and Food Sciences, University of Kentucky, 407 W. P. Garrigus Building, Lexington, KY 40546.
}

within the baseline confidence interval within $15 \mathrm{~min}$. Cows receiving cold water did not return to within the baseline confidence interval after a large decrease of $9.2 \pm 0.2^{\circ} \mathrm{C}$ during the 3 -h observational period. Moreover, a regression analysis of continued ascent in temperatures predicted that temperatures would return to baseline within $3.5 \mathrm{~h}$. These results demonstrate that, when cows consume large quantities of cold water, the effect of water intake is sizable and sustained. The value of reticular temperatures for daily monitoring in a production setting hinges largely on the implications of this impact.

Key words: reticular temperature, temperature monitoring, water intake

\section{INTRODUCTION}

Normal variation in temperature among individual animals is large and somewhat random (Hewitt, 1921; Simmons et al., 1965; Lefcourt et al., 1999). Although the literature is consistent with regard to the presence of diurnal variation in temperatures, considerable disagreement exists as to how and when this variation occurs, although it is likely attributable to varying ambient conditions and animal or breed characteristics. Debate exists as to how frequently temperatures need to be measured to detect differences in physiological responses (Lefcourt et al., 1999).

Generally, average daily body temperatures for cattle fall within a range of 38.0 to $39.4^{\circ} \mathrm{C}$ (Hewitt, 1921; Lefcourt et al., 1999; Hicks et al., 2001). Many physiological and management factors influence body temperature, including overall health, environment, ambient temperature, level of activity, estrus, pregnancy status, eating and drinking behavior, and excitement. Average body temperature varies by season, reflecting ambient temperatures, a phenomenon termed "seasonal drift" by Fordham et al. (1988).

Firk et al. (2002) suggested that the utility of a temperature monitor was highly dependent on its location. Attempts to measure body temperature of cattle were made for various anatomical locations including the rectum, ear (tympanic), vagina, reticulorumen, intraperitoneal cavity, and udder (milk). Hahn et al. 
(1990), in a comparison of 4 collection sites, concluded that internal sites of temperature measurement would be more useful indicators of body temperature during changing conditions than external sites of temperature measurement. Sievers et al. (2004) suggested that an intraruminal measuring system would be advantageous because it is independent of external disturbing factors, cannot be manipulated from the outside, and is less likely to be lost. Rumen temperatures were effective measures of core body temperature (Hicks et al., 2001; Prendiville et al., 2002). Because of the activity of heat-producing rumen microorganisms, ruminal or reticular temperatures are generally about $0.5^{\circ} \mathrm{C}$ greater than core body temperatures.

One concern and potential limitation with using a reticular temperature monitor is the effect of water intake on measured temperatures. Water consumption is known to temporarily, but dramatically, decrease rumen or reticular temperatures. Dramatic decreases in ruminal temperature occur after the cow drinks water (Simmons et al., 1965; Dracy and Kurtenbach, 1968; Yamada et al., 2001). It takes 20 to $120 \mathrm{~min}$ for temperatures to return to predrinking levels (Simmons et al., 1965; Brod et al., 1982; Yamada et al., 2001). The level of temperature depression is related to the amount and temperature of water consumed (Dracy and Kurtenbach, 1968; Brod et al., 1982). With $0^{\circ} \mathrm{C}$ water, this event is accompanied by a reduction in microbial activity (Brod et al., 1982). Depending on the frequency of temperatures actually influenced by water intake, the effect of water intake could be a potential barrier to the efficacy of rumen or reticular temperature collection for management purposes. Most research was conducted on sheep or nonlactating cattle many years ago with experimental devices, and the definitions of "return to normal" were lax. This work was undertaken to assess the impact of water intake on reticular temperatures collected with a commercially available device in lactating dairy cattle. The primary objective was to quantify the length of time required for reticular temperature to return to the predrinking level following a drinking bout.

\section{MATERIALS AND METHODS}

This research was conducted at the Purdue Dairy Research and Education Center (West Lafayette, IN). Care and use of cows was approved by the Purdue Animal Care and Use Committee. Reticular temperatures were collected using the phase IV Cattle Temperature Monitoring System (Phase IV Engineering Inc., Boulder, CO) marketed by MaGiiX (MaGiiX Inc., Post Falls, ID). Each cow in the 2 experiments was equipped with a phase IV bolus, a passive radio frequency transponder permanently residing in the reticulum of the cow. The bolus contained temperature-measuring electronics. When the animal passed a panel reader, radar sensors detected the animal, which turned on the transmitter. Then, a magnetic field induced an electrical charge inside the bolus, energizing the transmitter. In response to this interrogation signal, the bolus responded by transmitting its unique identification number and temperature on a coded radio frequency. This information was transmitted to an on-site computer and later to a server allowing simple, online viewing and downloading for further analyses.

Two separate experiments were conducted on January 16, 17, and 19, 2007 (experiment 1), and on June 5, 6, and 11, 2007 (experiment 2). Ambient weather conditions were recorded at 0.5 -h intervals at the Purdue Agronomy Research Farm, adjacent to the Purdue Dairy Research and Education Center. The mean maximum and minimum daily ambient temperatures for experiment 1 were $-2.2^{\circ} \mathrm{C} \pm 1.5$ and $-10.2^{\circ} \mathrm{C} \pm$ 3.9 , respectively. The mean maximum and minimum daily ambient temperatures for experiment 2 were $25.4^{\circ} \mathrm{C} \pm 4.5$ and $10.6^{\circ} \mathrm{C} \pm 2.5$, respectively. For both experiments, 9 mid- to late-lactation, high-production, low-SCC, second-lactation Holstein cows were selected from the herd. Because of the time elapsed between the 2 experiments, 2 different sets of cows were chosen with no overlap between experiments. Cows were assigned randomly to 3 treatments administered over $3 \mathrm{~d}$ in replicated $3 \times 3$ Latin squares with each cow receiving each treatment on 1 of the $3 \mathrm{~d}$. Water and feed access were restricted for a minimum of $2 \mathrm{~h}$ before water intake and for $3 \mathrm{~h}$ following water intake. Cows were housed individually in tie-stalls before and during administration of water treatments. Reticular temperatures were collected by continuously moving cows past 2 stationary reader panels (Figure 1). Before cows were given water, a series of reticular temperatures were collected and averaged to establish a pretreatment baseline reticular temperature for each cow. Water temperatures were recorded using a GLA M750 digital thermometer (GLA Agricultural Electronics, San Luis Obispo, CA) just before water was presented to the cow.

In experiment 1 , cows produced $41.7 \pm 4.3 \mathrm{~kg}$ of milk during the week before the first day of data collection, were $162.1 \pm 38.7 \mathrm{DIM}$ on the first day of data collection, and had $31,000 \pm 23,749 \mathrm{SCC} / \mathrm{mL}$ at the most recent DHI test. Four cows were pregnant and 5 were not pregnant. Cows were provided a 5- to 10 -min opportunity to drink water presented to them in plastic tubs. Any water that was not consumed was administered via oral drench to ensure that equal quantities of water were consumed. Water was administered using a Magrath Cattle Pump System (Magrath Co., McCook, 
$\mathrm{NE})$. Treatments were $25.2 \mathrm{~kg}$ of hot water $\left(34.3^{\circ} \mathrm{C} \pm\right.$ $1.0)$, warm water $\left(18.2^{\circ} \mathrm{C} \pm 0.4\right)$, or cold water $\left(7.6^{\circ} \mathrm{C}\right.$ $\pm 0.4)$. As soon as each cow was drenched with water, she was moved past the reader panels for the first posttreatment recording of temperatures.

Temperatures were collected as follows. First, each cow was moved past the first reader panel. Then, her rectal temperature was collected with a GLA M750 digital thermometer in a weigh station between the 2 reader panels (Figure 1). Last, she was moved past the second reader panel. At that point, she had access to an alley with exposure to ambient conditions for a short time. This process was repeated for $3 \mathrm{~h}$ after the last of the 9 cows was drenched with each cow sampled about every $15 \mathrm{~min}$.

In experiment 2 , cows produced $41.7 \pm 6.0 \mathrm{~kg}$ of milk during the week before the first day of data collection, were $188.2 \pm 66.8 \mathrm{DIM}$ on the first day of data collection, and had 58,888 $\pm 38,818 \mathrm{SCC} / \mathrm{mL}$ at the most recent DHI test. Four of the cows were pregnant and 5 were not pregnant. Because cows in trial 1 did not consume much of the water presented, all water was administered via oral drench to ensure that equal quantities of water were consumed. The amount of water provided was calculated using the maximum drinking bout size from Dado and Allen (1994). Treatments were $18.9 \mathrm{~kg}$ of body-temperature water $\left(38.9^{\circ} \mathrm{C} \pm 0.2\right)$, cold water $\left(5.1^{\circ} \mathrm{C} \pm 0.4\right.$ ), or control (no water). Rectal temperatures were recorded only before drenching water to ensure that all cows had normal rectal temperatures for the experiment. Without the need to record rectal temperatures, it was possible to move the cows past the recording panels more frequently in experiment 2. Cows were moved past both reader panels continuously for $3 \mathrm{~h}$ after the last of the 9 cows was drenched. A detour was created (Figure 1) so that cows had minimal access to the alley with exposure to ambient conditions. Facilities in which the cows were temporarily housed and in which the experiment was conducted used air that was tempered by venting through a geothermal temperature exchange system buried beneath the ground near the dairy. The first temperature recorded immediately following drenching was used as a reference point and a proxy for drenching time for all other temperatures for each cow. Temperatures were pooled and averaged at 15-min (experiment 1) and 5-min (experiment 2) intervals in relation to drenching time for each cow and treatment combination. A 95\% confidence interval (CI) for baseline temperature was created for each cow and treatment combination using her mean baseline temperature with the overall experimental standard error. This CI was used to determine if and when a cow returned to her baseline temperature following the water treatment. Similarly, a 95\% CI was

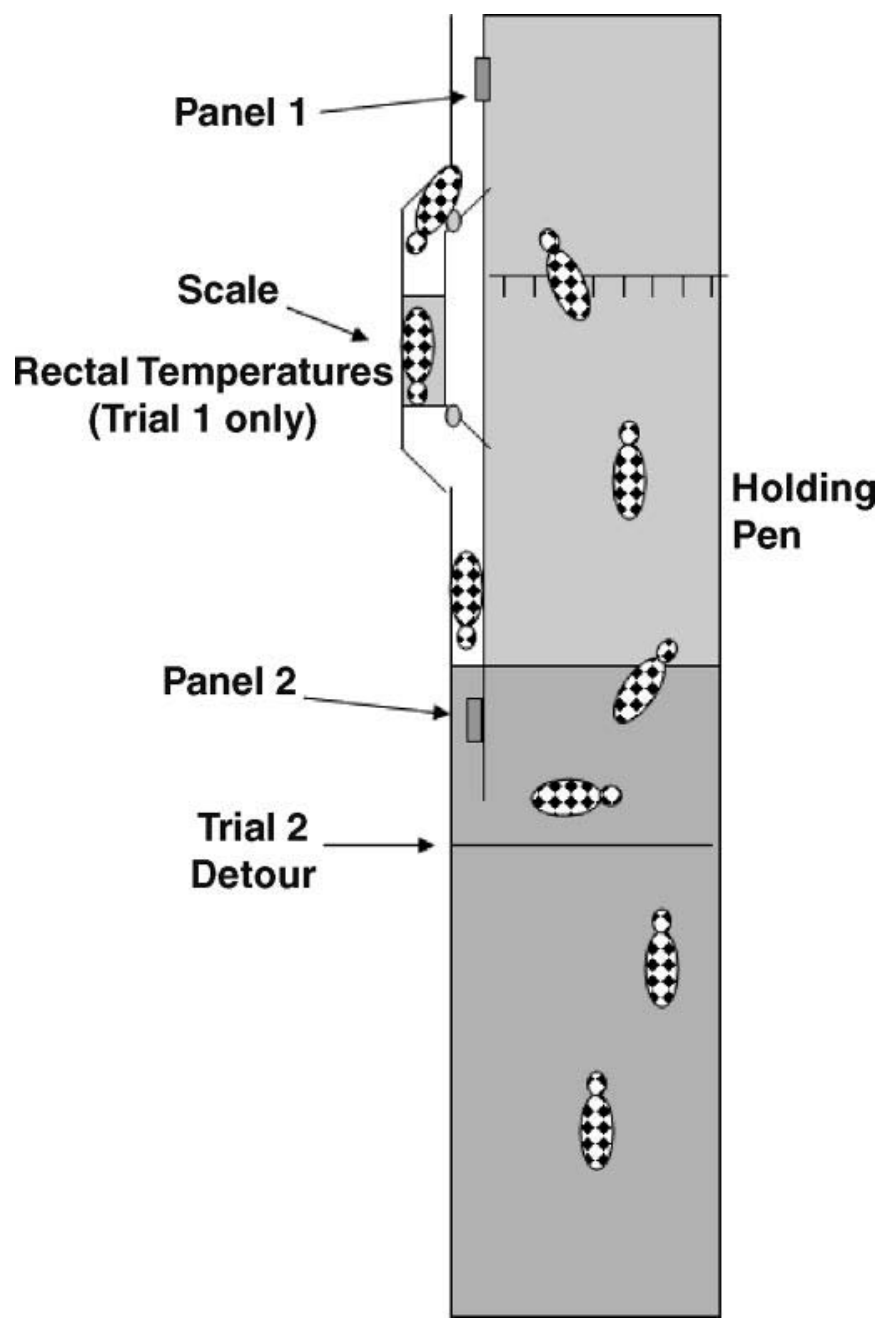

Figure 1. Layout of data collection area. In experiment 1, cows continuously passed panel 1 only, whereas, in experiment 2 , cows continuously passed both panels.

created for each treatment within experiment using the baseline treatment mean and the respective overall experimental standard error. This CI was used to define the point when temperature returned to baseline for the various treatments. For each experiment, the maximum decrease in reticular temperature by treatment was analyzed using the GLM procedure of SAS (SAS Institute, Cary, NC). Effects of cow, day, and treatment were tested. This same analysis was conducted for decrease in rectal temperature for experiment 1 . In experiment 2 , linear regression analysis using the GLM procedure of SAS was performed for each cow by day combination for the increase in temperature over the last hour of sampling. For each cow by day combination, reticular temperature was the dependent variable, and time since drenching was the only independent variable in each equation. Results of 

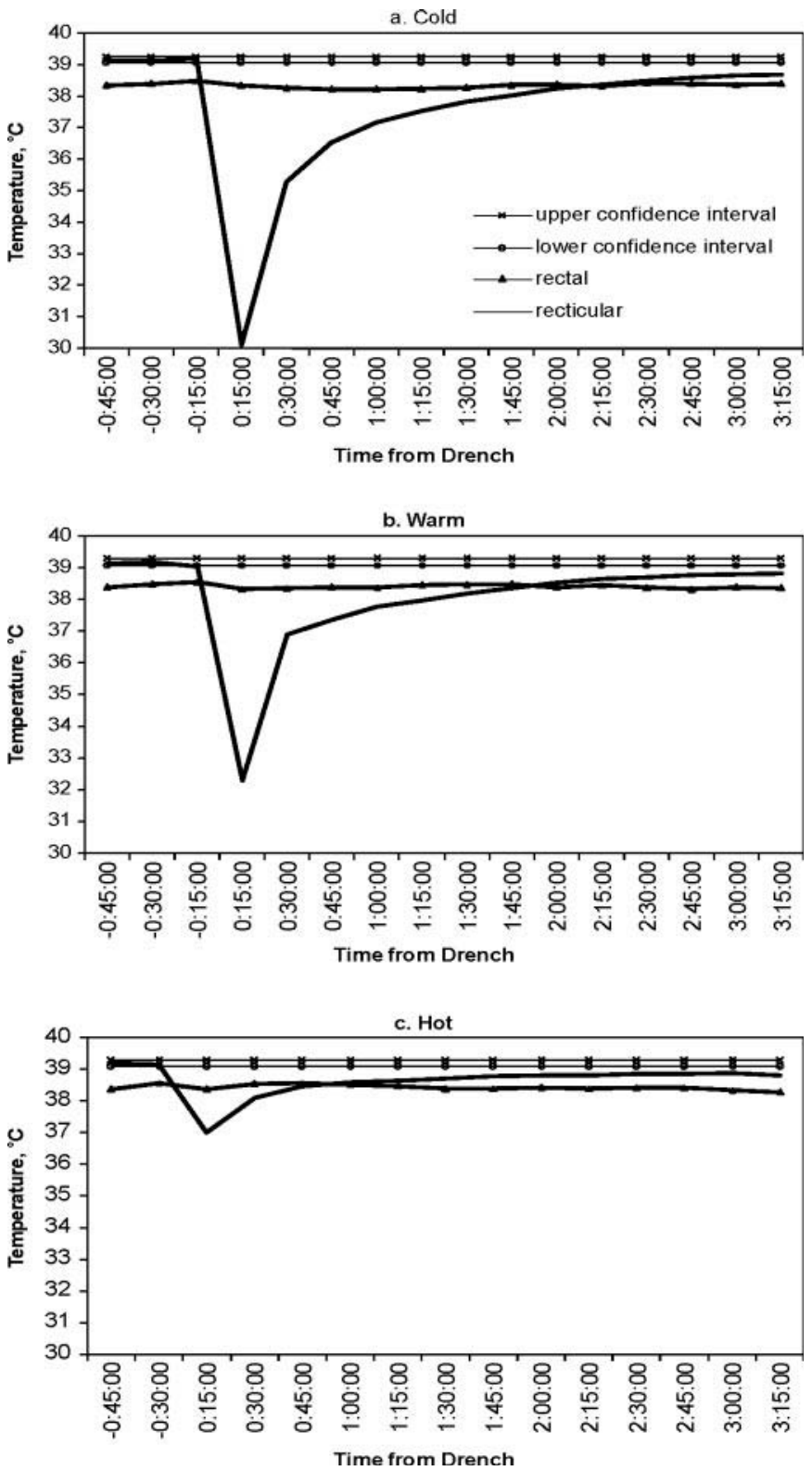

Figure 2. Experiment 1: reticular temperature response patterns for treatments involving consumption of a) cold water $\left(7.6^{\circ} \mathrm{C} \pm 0.4\right)$, b) warm water $\left(18.2^{\circ} \mathrm{C} \pm 0.4\right)$, and c) hot water $\left(34.3^{\circ} \mathrm{C} \pm 1.0\right)$.

these regression analyses were used to extrapolate the continued ascent in temperature beyond the sampling period. This extrapolation was carried out through 6 $\mathrm{h}$ after drenching time for each cow by day. Important limitations considered with this methodology were the assumptions of a linear increase in temperature and similar diurnal changes for each cow. Temperatures were averaged by treatment and sampling interval to create graphs of average changes in temperature for each treatment in each experiment (Figures 2 and 3).

\section{RESULTS}

In experiment 1 , the response to each treatment involved an immediate and dramatic decrease in reticular temperature followed by a rapid increase progressing toward the baseline temperature (Figure 2). Nevertheless, for each treatment, the treatment means did not return to the baseline temperatures during the recorded period, as defined by the $95 \%$ CI of the average pretreatment temperatures. For each treatment, the lowest temperature occurred for the period immediately following water ingestion. Although the temperatures increased rapidly after this initial decrease, the ascent in temperatures appeared to level after about $2 \mathrm{~h}$ for each treatment. The regression analysis $\left(\mathrm{R}^{2}=\right.$ 0.78 ) demonstrated the effect of treatment on decrease in temperature. Effect of water temperature was highly significant in this analysis $(P<0.0001)$, but there was no cow or day effect observed $(P>0.05)$. Least squares means for maximum decrease in temperature were 8.5 $\pm 0.5,6.9 \pm 0.5$, and $2.2 \pm 0.5^{\circ} \mathrm{C}$ for cold, warm, and hot water treatments, respectively (Figure 3). Using Tukey's test for multiple comparisons, the decrease in temperature for hot water was less than the decrease for cold $(P<0.0001)$ and warm $(P<0.0001)$, but the difference between cold and warm water was not different $(P=0.077)$. Examining each of the 27 cow by day combinations for a return to the baseline temperature range revealed that only 3 of the 27 combinations returned to the respective baseline temperature (Table 1) within the time allotted.

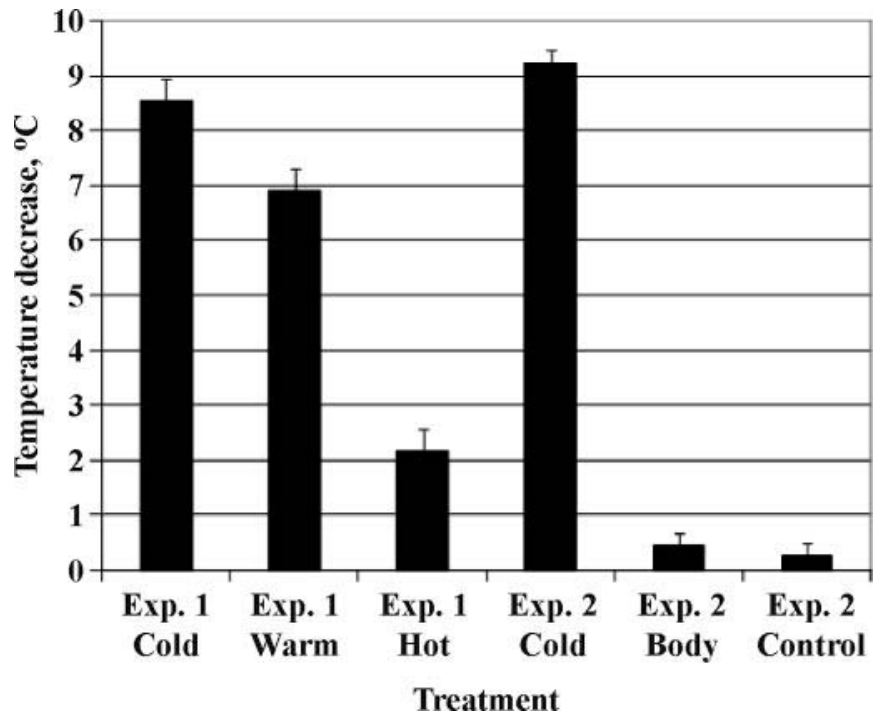

Figure 3. Least squares treatment means for maximum decrease in temperature for treatments in 2 experiments. Experiment 1: cold $=7.6^{\circ} \mathrm{C} \pm 0.4$; warm $=18.2^{\circ} \mathrm{C} \pm 0.4$; hot $=34.3^{\circ} \mathrm{C} \pm 1.0$; experiment 2 : cold $=5.1^{\circ} \mathrm{C} \pm 0.4 ;$ body temperature $=38.9^{\circ} \mathrm{C} \pm 0.2 ;$ and control $=$ no water. 
Table 1. Proportion of cows returning to baseline temperature after consumption of water at divergent temperatures

\begin{tabular}{lc}
\hline Water temperature & Proportion \\
\hline Experiment 1 & \\
Cold $\left(7.6^{\circ} \mathrm{C} \pm 0.4\right)$ & $0 / 9$ \\
Warm $\left(18.2^{\circ} \mathrm{C} \pm 0.4\right)$ & $1 / 9$ \\
Hot $\left(34.3^{\circ} \mathrm{C} \pm 1.0\right)$ & $2 / 9$ \\
Experiment 2 & $3 / 9$ \\
Cold $\left(5.1^{\circ} \mathrm{C} \pm 0.4\right)$ & $8 / 9$ \\
Body temperature $\left(38.9^{\circ} \mathrm{C} \pm 0.2\right)$ & $8 / 9$ \\
Control (no water) & \\
\hline
\end{tabular}

Rectal temperatures remained consistent throughout the observation period for each treatment even after water intake in experiment 1 (Figure 2). A regression analysis of maximum decrease in rectal temperatures demonstrated that there was no significant effect of treatment, day, or cow $(P>0.05)$ on decline in rectal temperature. In experiment 2 , pretreatment rectal temperatures were $38.5^{\circ} \mathrm{C} \pm 0.2$ with a range from 38.2 to $38.9^{\circ} \mathrm{C}$. The reticular temperatures of control cows behaved as expected with the temperatures remaining within the calculated CI throughout most the observation period (Figure 4). The exceptions were a few observations in which the reticular temperatures actually increased above the CI for a short time. The reticular temperatures for cows receiving the body-temperature water decreased slightly following water administration, but returned to within the baseline temperature CI within $15 \mathrm{~min}$. The reticular temperatures for cows receiving the cold water changed similarly to those in experiment 1 , with a dramatic decrease in temperature $\left(9.2 \pm 0.2^{\circ} \mathrm{C}\right)$ followed by a rapid ascent toward the baseline temperatures. Again, the reticular temperatures did not return to within the baseline CI within the observation period. In this case, as opposed to experiment 1 , the temperatures were increasing at the end of the observation period. Therefore, we performed a regression analysis for each cow-day combination to use in prediction of the continued increase in temperature beyond the period of observation. This extrapolation predicted that, had temperatures been measured for a longer period, the cows would have returned to temperatures within the baseline $\mathrm{CI}$ within $3.5 \mathrm{~h}$ following water intake. As in experiment 1, the magnitude of drop in temperature and progression toward the baseline were affected by water temperature. The regression analysis of decrease in temperature $\left(R^{2}=0.98\right)$ demonstrated the impact of treatment on decrease in temperature. Treatment was highly significant $(P<$ $0.0001)$, but there was no cow or day effect observed $(P$ $>0.05$ ). Least squares means for maximum decrease in temperature were $9.2 \pm 0.2,0.4 \pm 0.2$ and $0.3 \pm 0.2^{\circ} \mathrm{C}$ for cold water, body-temperature water, and control treat- ments, respectively (Figure 3). Using Tukey's test for multiple comparisons, the decrease in temperature for cold water was more than that for body-temperature water $(P<0.0001)$ and control $(P<0.0001)$, but the difference between body-temperature water and control was not different $(P=0.851)$. Examining each of the 27 cow-day combinations for return to baseline temperature range demonstrated that 8 of 9 control cows, 8 of 9 body-temperature water cows, and 3 of 9 cold water cows returned to their respective baseline temperatures during the observation period (Table 1). Interestingly, it was the same cow that did not return to baseline temperature when she received both the control and body-temperature water treatments. The average time to return to the baseline CI, including extrapolated values, were 0:00:30 $\pm 0: 13: 10,0: 14: 49 \pm 0: 13: 10$, and 3:28:50 \pm 0:12:25 for control, body-temperature water, and cold water treatments, respectively.

\section{DISCUSSION}

Variation exists within literature as to the effect of water intake on rumen or reticulum temperatures. Using sheep and measuring temperatures within the reticulum, Dracy et al. (1963) concluded that regardless of the quantity of water or the level of decrease in temperature, reticular temperatures returned toward normal intrareticular temperatures within $60 \mathrm{~min}$. Yet with the actual data, the difference was as much as $1.2^{\circ} \mathrm{C}$ after $60 \mathrm{~min}$. Cunningham et al. (1964) demonstrated that $21.1 \pm 3.9 \mathrm{~kg}$ of $1.1^{\circ} \mathrm{C}$ water induced a decrease of $12.8,4.7$, and $1.3^{\circ} \mathrm{C}$ for lower, middle, and upper rumen temperatures, respectively. In lactating dairy cows (2 Ayrshires, 1 Guernsey, and 1 Holstein), Simmons et al. (1965) observed reticular temperatures as low as $32^{\circ} \mathrm{C}$ with time to recovery to predrinking levels of about 1.5 h. In sheep, Brod et al. (1982) concluded that $108,96,96$, and 72 min passed before temperatures returned to within $0.5^{\circ} \mathrm{C}$ of initial rumen temperatures after 2 -L water treatments of $0,10,20$, and $20^{\circ} \mathrm{C}$, respectively. In another sheep study, 2 to 3 $\mathrm{h}$ passed before rumen temperatures leveled off after ingestion of water (Noffsinger et al., 1961). Yamada et al. (2001), using a thermistor sensor in the rumen of fistulated steers, observed that rumen temperatures decreased by about $6^{\circ} \mathrm{C}$ within $2 \mathrm{~min}$, but returned to basal levels within $20 \mathrm{~min}$.

This pattern of change in temperatures following a drinking bout in this experiment supports previous work (Cunningham et al., 1964; Bhattacharya and Warner, 1968; Dracy and Kurtenbach, 1968). Dracy and Kurtenbach (1968) suggested that this pattern occurred because ingested liquid was mixed with existing ruminal reticular contents initially resulting in the 
rapid increase in temperature soon after liquid ingestion. After the initial increase, body heat was needed to warm the contents of the reticulorumen. Clearly, the magnitude of this decrease in temperature was greater with decreasing water temperature. The results from experiment 1 were somewhat surprising in that none of the treatments returned to the baseline as expected. The rapid increase in reticular temperatures with each treatment likely demonstrated that the effect of water intake was temporary and that temperatures within the reticulum quickly increased toward actual core body temperature. The lack of an effect of water treatment on rectal temperatures indicates that water intake did not have an effect on core body temperature. Rather, the impact was limited to the environmental conditions of the reticulum where the water remained for some unspecified period. This contrasts the previous work demonstrating a decrease in rectal temperatures associated with ingestion of cold water (Milam et al., 1986; Stermer et al., 1986; Wilks et al., 1990).

Differences in temperature responses to water intake between the 2 experiments may reflect differences in ambient temperature and season. The effect of environmental conditions on reticular and rectal temperatures was reflective of current ambient conditions and long-term adaptation to seasonal temperatures. The increase in reticular temperatures after treatment was greater in experiment 2 than experiment 1 , which may be partly explained by thermal adaptation to ambient conditions. Furthermore, restricting feed and water access for the observation period, which was necessary for control of the reticulorumen environment, may have influenced the flow of water through the reticulorumen (Seo et al., 2007).

The minor decrease in temperature observed for control cows may partly reflect the impact of this restriction. Moreover, without new feed being introduced into the digestive system, the activity of the rumen microbial population would likely decrease. In turn, the heat generated from microbial fermentation would likewise decrease, further decreasing the temperature in the reticulum. Rumen temperature of fed cows was greater than that of fasted cows (Brody et al., 1955). With $0^{\circ} \mathrm{C}$ water in sheep, microbial activity was suppressed, as evidenced by elevated $\mathrm{pH}$ and depressed concentrations of volatile fatty acids and ammonia-N (Brod et al., 1982).

The design of experiment 2 was altered, in part, to help answer some of the questions that arose from the results of experiment 1 . A control group was included to assess the potential impact of a treatment using water at temperatures similar to body temperature to determine if the act of water ingestion affected reticular temperatures. Reticular temperatures were
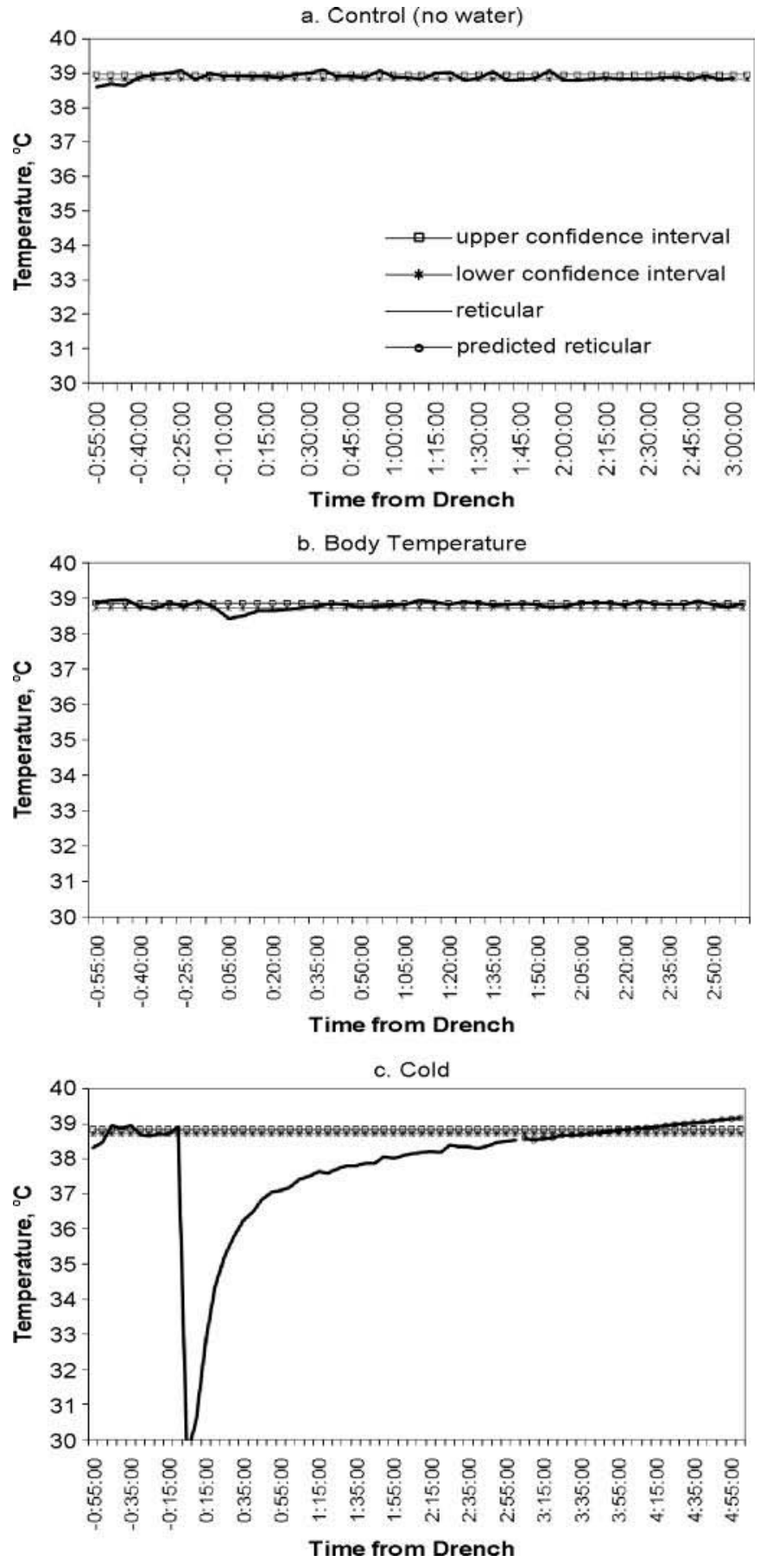

Figure 4. Experiment 2: reticular temperature response patterns for treatments involving consumption of a) no water (control), b) body-temperature water $\left(38.9^{\circ} \mathrm{C} \pm 0.2\right)$, and c) cold water $\left(5.1^{\circ} \mathrm{C} \pm\right.$ $0.4)$.

not altered with the control cows. When cows were presented with body-temperature water, only a slight and temporary reduction in reticular temperatures was observed. These results demonstrate that the decrease in temperature and pattern of ascent in temperature 
within the cold-treatment cows were a result of the ingestion of cold water. The simple ingestion of even relatively large volumes of water has minimal impact on reticular temperatures.

Because of concerns for the welfare of the animals in the study arising from deprivation of food and water along with constant standing and movement on concrete, we elected not to extend the observation period beyond $3 \mathrm{~h}$ after water intake. It is likely that cows given cold water would have continued to increase in temperature as the regression equations used to extrapolate beyond the observation period would suggest. Under this assumption, cows required $3.5 \mathrm{~h}$ to return to the baseline temperature CI. Although it is encouraging, that, unlike in experiment 1 , these cows were more likely to reach their baseline temperatures, this period seems exceedingly long. Chilled water has been suggested as a potential means of reducing the effects of heat stress through reduction of core body temperature (Milam et al., 1986).

From these experiments, it is clear that water intake has an immediate, dramatic effect on temperatures measured in the reticulum, but the length of this effect remains somewhat unclear. How these results translate to field conditions, where water consumed may generally be warmer and feed intake not restricted, is unclear. Further, cows consume reduced quantities of water at low temperatures (Milam et al., 1986). Because of the stationary panels required to read the boluses using the Cattle Temperature Monitoring System, this question cannot be answered with this system. Ideally, a technology that would provide continuous readings of reticular temperatures in a natural environment using a greater number of animals over a longer period could be used to more accurately determine how long reticular temperatures are affected by water intake.

Given the impact of water intake on reticular temperatures, producers considering using the Cattle Temperature Monitoring System or similar technologies would best be served by placing the reader panels in a location where it is unlikely cows recently had access to water. For many dairy operations, this makes the exit lane leaving a parlor an ideal location for these panels. It would be advantageous to provide tepid (e.g., from a plate cooler) water to cows, reducing the effect observed with warmer water. The value of reticular temperatures for daily monitoring in a production setting hinges largely on the implications of this effect. Additional research is needed to determine if reticular temperatures are of value in a production setting regardless of the impact of water intake. Certainly, a reticular temperature bolus that recorded temperatures more frequently would be more apt to circumvent this concern.

\section{CONCLUSIONS}

When large volumes of water are consumed at divergent temperatures, the effect of water intake on reticular temperatures may persist for longer than previous estimates indicated. The simple ingestion of water had minimal impact on reticular temperatures as indicated by the response of cows receiving body-temperature water. In contrast to other studies, rectal temperatures were not affected by water intake in our study. The magnitude of decrease in temperature along with the time to return to a baseline temperature was affected by the temperature of the water consumed. Responses to water intake vary by environmental conditions and by cow. These results demonstrate that, when cows consume large quantities of cold water, the effect of water intake is sizable and sustained.

\section{ACKNOWLEDGMENTS}

The authors acknowledge the staff of the Purdue Dairy Research and Education Center, C. J. Fleenor, and Michele Jones for their assistance in data collection. Len Wallace (MaGiiX Inc.) is recognized for his financial contributions to this project and ongoing work at the Purdue Dairy Research and Education Center.

\section{REFERENCES}

Bhattacharya, A. N., and R. G. Warner. 1968. Influence of varying rumen temperature on central cooling or warming and on regulation of voluntary feed intake in dairy cattle. J. Dairy Sci. 51:1481-1489.

Brod, D. L., K. K. Bolsen, and B. E. Brent. 1982. Effect of water temperature on rumen temperature, digestion and rumen fermentation in sheep. J. Anim. Sci. 54:179-182.

Brody, S., G. E. Dale, and R. E. Stewart. 1955. Environmental physiology and shelter engineering. XXXVI. Interrelations between temperatures of rumen (at various depths), rectum, blood, and environmental air; and effects of an antipyretic, feed and water consumption. Missouri Agric. Exp. Sta. Res. Bull. 539.

Cunningham, M. D., F. A. Martz, and C. P. Merilan. 1964. Effect of drinking-water temperature upon ruminant digestion, intraruminal temperature, and water consumption of nonlactating dairy cows. J. Dairy Sci. 47:382-385.

Dado, R. G., and M. S. Allen. 1994. Variation in and relationships among feeding, chewing, and drinking variables for lactating dairy cows. J. Dairy Sci. 77:132-144.

Dracy, A. E., W. O. Essler, and J. R. Jahn. 1963. Recording intrareticular temperature by radiosone equipment. J. Dairy Sci. 46:241-242.

Dracy, A. E., and A. J. Kurtenbach. 1968. Temperature change within the rumen, crop area, and rectal area when liquid of various temperatures was fed to calves. J. Dairy Sci. 51:1787-1790.

Firk, R., E. Stamer, W. Junge, and J. Krieter. 2002. Automation of oestrus detection in dairy cows: A review. Livest. Prod. Sci. 75:219-232.

Fordham, D. P., P. Rowlinson, and T. T. McCarthy. 1988. Oestrus detection in dairy cows by milk temperature measurement. Res. Vet. Sci. 44:366-374. 
Hahn, G. L., R. A. Eigenberg, J. A. Nienaber, and E. T. Littledike. 1990. Measuring physiological responses of animals to environmental stressors using a microcomputer-based portable datalogger. J. Anim. Sci. 68:2658-2665.

Hewitt, E. A. 1921. A preliminary study of the normal variation in temperature of cattle. J. Am. Vet. Med. Assoc. 58:544-548.

Hicks, L. C., W. S. Hicks, R. A. Bucklin, J. K. Shearer, D. R. Bray, P. Soto, and V. Carvalho. 2001. Comparison of methods of measuring deep body temperature of dairy cows. Pages 432-438 in 6th International Symposium. Am. Soc. Agric. Eng., Louisville, KY.

Lefcourt, A. M., J. B. Huntington, R. M. Akers, D. L. Wood, and J. Bitman. 1999. Circadian and ultradian rhythms of body temperature and peripheral concentrations of insulin and nitrogen in lactating dairy cows. Domest. Anim. Endocrinol. 16:41-55.

Milam, K. Z., C. E. Coppock, J. W. West, J. K. Lanham, D. H. Nave, J. M. Labore, R. A. Stermer, and C. F. Brasington. 1986. Effects of drinking water temperature on production responses in lactating Holstein cows in summer. J. Dairy Sci. 69:1013-1019.

Noffsinger, T. L., K. K. Otagaki, and C. T. Furukawa. 1961. Effect of feed and water intake on rumen and body temperatures of sheep under subtropical conditions. J. Anim. Sci. 20:718-722.

Prendiville, D. J., J. Lowe, B. Earley, C. Spahr, and P. Kettlewell. 2002. Radiotelemetry systems for measuring body temperature. Grange Research Centre, Dunsany, Ireland.
Seo, S., C. Lanzas, L. O. Tedeschi, and D. G. Fox. 2007. Development of a mechanistic model to represent the dynamics of liquid flow out of the rumen and to predict the rate of passage of liquid in dairy cattle. J. Dairy Sci. 90:840-855.

Sievers, A. K., N. B. Kristensen, H.-J. Laue, and S. Wolffram. 2004. Development of an intraruminal device for data sampling and transmission. J. Anim. Feed Sci. 13(Suppl. 1):207-210.

Simmons, K. R., A. E. Dracy, and W. O. Essler. 1965. Diurnal temperature patterns in unrestrained cows. J. Dairy Sci. 48:1490-1493.

Stermer, R. A., C. F. Brasington, C. E. Coppock, J. K. Lanham, and K. Z. Milam. 1986. Effect of drinking water temperature on heat stress of dairy cows. J. Dairy Sci. 69:546-551.

Wilks, D. L., C. E. Coppock, J. K. Lanham, K. N. Brooks, C. C. Baker, W. L. Bryson, R. G. Elmore, and R. A. Stermer. 1990. Responses of lactating Holstein cows to chilled drinking water in high ambient temperatures. J. Dairy Sci. 73:1091-1099.

Yamada, A., M. Sutoh, and T. Imura. 2001. The changes of rumen temperature with grazing behavior in the daytime. Grassl. Sci. $47: 491-493$ 